\title{
COMENTÁRIO
}

\section{"A FILOSOFIA DA PSICOLOGIA E O "NOVO MÉTODO" FILOSÓFICO NOS ESCRITOS TARDIOS DE WITTGENSTEIN: UMA RELAÇÃo PRÁTICA E NECESSÁRIA”, DE GILBERTO FERreira de Souza}

Pedro Karczmarczyk $k^{1}$

Referência do texto comentado: SOUZA, Gilberto Ferreira de. A filosofia da psicologia e o "novo método" filosófico nos escritos tardios de Wittgenstein: uma relação prática e necessária. Trans/Form/Ação: revista de filosofia da Unesp, vol. 43, Número Especial, p. 177-200, 2020.

El artículo busca establecer la novedad metodológica de las observaciones de Wittgenstein sobre la filosofía de la psicología y su condición de clave hermenéutica de sus escritos sobre este tópico. El artículo se compromete implícitamente a poner de relieve la novedad del pensamiento de Wittgenstein respecto de tres parámetros que examinaremos a continuación: 1) con la concepción tradicional de la filosofía, revolucionada por la concepción de Wittgenstein. 2) entre el método del Tractatus y el desarrollado luego del regreso a Cambridge en 1929. Y finalmente, puesto que el "nuevo método de la filosofía de la psicología” no se correspondería con el método general desarrollado desde 1929, sino con un nuevo método presente en los escritos sobre ese tópico elaborados hacia 1940, y conocidos a partir de 1980: 3) un

\footnotetext{
${ }^{1}$ Profesor de Filosofía contemporánea en la Universidad Nacional de La Plata, Argentina. Investigador en el Consejo Nacional de Investigaciones Científicas y Técnicas (Conicet), La Plata - Argentina.

(D) https://orcid.org/0000-0001-6566-915X E-mail: pedrokarcz@hotmail.com

http://doi.org/10.1590/0101-3173.2020.v43esp.15.p201
}

\section{(1)}

This is an open-access article distributed under the terms of the Creative Commons Attribution License. 
contraste con el método desarrollado desde 1929, para caracterizar el corte de circa 1940.

1) se desarrolla mediante una somera caracterización de la concepción tradicional de la filosofía, en la cual el ideal del método científico empujaría a filósofos y filósofas a buscar hipótesis y teorías explicativas. De aquí surge una caracterización del propósito del método wittgensteiniano: liberar al filósofo del influjo del método científico.

2) Ferreira considera que, en el Tractatus, la filosofia es concebida como "uma atividade cujo fim é o esclarecimento lógico dos pensamentos anteriormente turvos e indistintos", y que esta es la razón por la cual el libro es "um instrumento utilizado para essa finalidade e descartado em seguida". Ahora bien, de esta caracterización del propósito del Tractatus no se sigue que el libro deba ser descartado. Muchos libros orientados a la clarificación lógica del pensamiento (de Frege o Russell para comenzar) no tuvieron necesidad de utilizar la metáfora de la escalera. La clarificación lógica de los pensamientos era para Wittgenstein un medio, un instrumento o un método, y no un fin en sí mismo, algo que el austríaco deja claro en la carta le dirigió a von Ficker (WITTGENSTEIN, 1969, p. 96-97).

Ferreira no distingue adecuadamente entre objetivos y métodos (o entre estrategias y tácticas), lo que tiene graves consecuencias en su artículo. En efecto, Ferreira pone como premisa la ausencia de reflexión sobre los conceptos psicológicos en el Tractatus (una premisa injusta, ya que el Tractatus contiene una aguda reflexión sobre las actitudes proposicionales en general y sobre el problema del solipsismo en particular) ausencia que sería la fuente de un conjunto de presuposiciones no examinadas sobre los conceptos psicológicos, piedra de toque de los desarrollos posteriores.

3) respecto de este contraste el artículo no provee un argumento sólido, pero sí varias contradicciones. Ferreira sugiere en varias ocasiones que el mismo método estaría siendo aplicado a las matemáticas y a la psicología: "na psicologia existem métodos experimentais, enquanto na matemática existem métodos demonstrativos, e em ambas existe confusão conceptual” diluyendo así la especificidad temática del método que el propio Ferreira defiende y extendiendo a las matemáticas las consideraciones finales de las Investigaciones filosóficas. Se trata a nuestro entender de un evidente achatamiento de las diferencias, ya que la confusión conceptual en psicología pone en entredicho la cientificidad de esta disciplina, pero en matemáticas no está en cuestión la 
demostración matemática en cuanto tal, un juego de lenguaje establecido hace milenios, sino las concepciones filosóficas que aquejan al desarrollo de esta disciplina, de las cuales la crisis de los fundamentos de las matemáticas son un ejemplo sobresaliente.

Lo que hemos dicho muestra lo que nos resulta cuestionable en la anatomía del argumento de Ferreira. Nuestro juicio no mejora sin embargo cuando juzgamos este argumento por los resultados que induce. La homogeneización de disciplinas con estatutos epistemológicos diversos que venimos de considerar es, sin dudas, una pesada consecuencia de una elucidación insuficiente del problema del método.

Sin embargo, lo más grave es, a nuestro entender, no afrontar decididamente la dificultad filosófica crucial: ¿cuál es el estatuto de los enunciados filosóficos de Wittgenstein, es decir, de las elucidaciones gramaticales? ¿cómo es posible que, si el método propugna descripciones desde múltiples perspectivas, sus resultados, las múltiples descripciones, sin embargo, carezcan de todo carácter hipotético? Puesto en otros términos, el problema es que un enunciado que pretende describir una norma lingüística, puede estar reformando la práctica lingüística, interviniendo sobre la misma. Si las descripciones se pueden realizar desde diferentes perspectivas, y ser por tanto diferentes, ¿`ómo elegir entre las mismas? ¿cómo se ordena este dominio? Y si pudiéramos resolver este problema, ¿no acabaríamos desarrollando una filosofía sistemática? (RORTY, 1998; WAISMANN (1968), LANCE \& O'LEARY-HAWTHORNE (1997); BAKER (2004)). Este problema se vuelve inaccesible para el autor del artículo desde el momento en que pasó por alto el estatuto del silencio en el Tractatus, aquello que Habermas, con gusto por las paradojas, caracterizó como una filosofía trascendental no afirmativa. (HABERMAS, 1996, p. 207).

No podemos evitar señalar algunas otras peculiaridades del artículo. Es errónea la reducción de la psicología a la psicología conductista, ya que el desarrollo de la psicología incluyó una corriente introspectivista conducida por Oswald Külpe, con sede en Würzburg, de la que Wittgenstein tenía conocimiento. (MULLIGAN (2012); BARTLEY (1974); KAPLAN (1971); BLOOR (1983)). Es también llamativa la profusión en el artículo de expresiones como "usos conceptuais" y "usos dos conceitos", ya que las mismas sustituyen a las palabras por los conceptos en cuanto observables de la descripción gramatical. También sorprende la ausencia, a lo largo del artículo, de la mención de un ejemplo concreto en el cual el método muestre 
sus beneficios. Pero lo más sorprendente es que si la concepción del método es la clave hermenéutica de los escritos wittgensteinianos, Ferreira llegue a resultados exegéticos tan pobres, como comprometerse con una concepción que engloba a todos los conceptos psicológicos como "estados psicológicos o mentales" (entre los cuales Ferreira incluye a la creencia) evitando distinguir entre los conceptos psicológicos que remiten a estados genuinos, dotados de duración e intensidad (el dolor nos da aquí un paradigma) y las capacidades (como la comprensión) que poseen una gramática diversa. Esta confusión, lleva a Ferreira nada menos que a sostener que los fenómenos psicológicos son vivencias en primera persona, propias y exclusivas del sujeto, atribuyendo así a Wittgenstein el compromiso la concepción que el austríaco cuestionó tal vez definitivamente con el argumento del lenguaje privado.

\section{REFERÊNCIAS}

BAKER, Gordon Wittgenstein's Method. Neglected Aspects. Londres: Blackwell, 2004. BARTLEY, William. Wittgenstein. Londres: Quarter Books, 1974.

BLOOR, David Wittgenstein. A Social Theory of Knowledge, Londres, Routledge, 1983. HABERMAS, Jürgen La lógica de las ciencias sociales. Madrid: Tecnos, 1996. KAPLAN, Bernard. Wittgenstein Influences. Idealistic Studies. N. 1, 1971. LANCE, Mark Norris; O'LEARY-HAWTHORNE, John. The Grammar of Meaning Normativity and Semantic Dicourse. Cambridge: Cambridge University Press, 1997. MULLIGAN, Kevin. Wittgenstein et la philosophie austro-allemande. París: Vrin, 2012.

RORTY, Richard El giro lingüístico. Barcelona: Paidós, 1998.

WAISMANN, Friedrich How I see Philosophy. Londres: Palgrave-Macmillan, 1968. WITTGENSTEIN, Ludwig Briefe an Ludwig von Ficke. Salsburgo: Otto Müller, 1969.

Recebido: 05/06/2020

Aceito: 27/06/2020 